\title{
Morphometry of Pectoralis Quartus Muscle: A Rare Case Report of a Muscular Extranumary Cluster
}

\author{
Eduardo Poletti Camara, ${ }^{1}$ Antonio Geraldo Camara, ${ }^{2}$ Antonio José Assis Xavier de Souza Pinto, ${ }^{3}$ Valéria Paula \\ Sassoli Fazan, ${ }^{4}$ Marcelo Rodrigo Tavares ${ }^{5}$
}

\begin{abstract}
'Departament of Anatomy, Universidade José do Rosário Vellano (UNIFENAS). Alfenas, MG, Brazil
${ }^{2}$ Medical Doctor, Centro de Medicina Integrada (CMI). Ribeirão Preto, SP, Brazil

${ }^{3}$ Departament of Anatomy, Universidade José do Rosário Vellano (UNIFENAS). Alfenas, MG, Brazil

${ }^{4}$ Department of Surgery and Anatomy, School of Medicine of Ribeirão Preto, University of São Paulo (FMRP-USP), Ribeirão Preto, SP, Brazil ${ }^{5}$ Departament of Anatomy, Universidade José do Rosário Vellano (UNIFENAS). Alfenas, MG, Brazil
\end{abstract}

Disclose and conflicts of interest: none to be declared by all authors

\begin{abstract}
During a routine dissection in the thoracic region of a 70-year-old male cadaver, an anatomical variant was noted. Based on its anatomical characteristics, the supernumerary muscle was recognized as the pectoralis quartus muscle, being $10.05 \mathrm{~mm}$ wide and $9.0 \mathrm{~cm}$ long. Measurements were performed with the aid of a millimeter caliper. The corpse was treated with glycerin and local conservation methods, the photos were taken through an $8 \mathrm{Mp}$ camera with a resolution of $3264 \times 2448$ pixels. The presence of a morphometry becomes essential to characterize their proportions and further expand the studies of these specimens and their effective cataloging, characteristics that should be considered in the clinical study and subsequent treatment of the patient.
\end{abstract}

Keywords: Muscle variation; Gross anatomy, Human anatomy; Morphometry

\section{Introduction}

The presence of extranuminal bundles along the middle axillary line has been rarely reported. The pectoralis quartus muscle (Birmingham, 1889; Huntington, 1905) arises near the costochondral junction of the fifth and sixth ribs. Extending laterally to the rectus abdominis along the edge of the pectoralis major and being separated from it, this is a flat triangular band (Sawada et al) with an average width of $1 \mathrm{~cm}$. It pierces the armpit to be inserted near the surface of the tendon of the pectoralis major muscle and has relatively constant characteristics. Both its origin and insertion may be accompanied by a connective tissue band, axillary arch and other accessory muscles. The present report deals with the presence of a similar muscle, observed on the left side of the chest wall of a male cadaver during routine dissection.

\section{Case report}

We present a case of a right unilateral occurrence of an accessory head of the pectoralis major muscle in a 70-year-old male cadaver. No other anomalies or thoracic procedures performed in the axillary region were observed and evidenced. The muscle was discovered during a routine dissection to prepare new biological material for the academic year that would take place at José do Rosário Vellano University during the first semester of 2018. The corpse was treated with glycerin and local conservation methods, photos were taken. performed through an $8 \mathrm{Mp}$ camera with $3264 \times 2448$ pixel resolution. In the first resort, the pectoralis quartus muscle is a thin rectangular muscle (10.05 mm wide and $9 \mathrm{~cm}$ long) superficially inserted into the axillary neuro vascular bundle. The arterial supply is provided by a branch of the lateral thoracic artery, which surrounds the lower edge of the pectoralis major muscle to enter the middle of its muscular belly. Innervation is given through a branch of the medial pectoral nerve, which crossed the axillary artery inferiorly in the muscle innervation near its insertion into the tendon of the pectoralis major muscle. From its point of origin it progresses to the tendon of the pectoralis major muscle. The muscle fibers of the pectoralis quartus are deep but distinctly separate from the pectoralis major and pectoralis minor. The pectoralis quartus announced, results from non-fusion with the tendon fibers of the pectoralis major muscle at the time of normal anatomical rotation, before fixation on the lateral lip of the humeral bicipital groove. The minor pectoral muscle showed no abnormalities, as did the major pectoral muscle. 


\section{Discussion}

The pectoral muscles make up the anterior wall of the axillary region and are responsible for shaping the outer wall of the chest cavity. The pectoralis major is described in the literature as having a clavicular head and a costal sternal head. ${ }^{2}$ The clavicular head originates from the anterior surface of the medial half of the clavicle. Therefore, the costal sternal head originates from the anterior surface of the sternum, from the $2^{\text {nd }}$ costal cartilage to the 6th rib, and from the external oblique muscle aponeurosis. ${ }^{2,3}$ The pectoralis major has its insertion in the lateral lip of the Inter tubercular humerus sulcus. ${ }^{2,4,5}$ The pectoralis, on the other hand, originates from the third-fifth rib near the costal cartilages and its inserts are located on the medial and superior surfaces of the scapular coracoid process. 2 They are responsible for helping to stabilize the scapula and control some arm movements by pulling the inferior scapula and anteriorly against the chest wall., ${ }^{2,3}$ The pectoralis minor muscle is a demarcation commonly used during axillary surgery, so an anatomical variation in this region should be considered to avoid confusion or complications during surgical procedures in this locality. ${ }^{2,3,4}$

Innervation for the pectoralis major is provided through the lateral and medial portion of the pectoral nerves at all their segmental levels, since the pectoralis minor is innervated by the medial pectoral nerve at levels C8-T1. The clavicular head of the pectoralis major is commonly innervated by $\mathrm{C} 5-\mathrm{C} 6$, while the costal sternal head is innervated by $\mathrm{C} 7-\mathrm{T} 1$. The pectoralis quartus muscle found in the anterior portion of the chest wall originates from the rectus abdominis muscle, the lateral margin of the pectoralis major muscle, or the costal cartilages of the $5^{\text {th }}$ and 6th ribs, and its insertion into the pectoralis major or the tendon of the head. biceps brachis short muscle. ${ }^{6}$ ${ }^{7}$ In the muscle variation investigated in the present case, the insertion was similar to that of the previous authors, but the pectoralis major showed no absence of torsion present in conjunction with the pectoralis quartus muscle, in most cases. ${ }^{3,4}$ Another interesting fact is that of Arican et al. describe the presence of the pectoralis quartus muscle in agreement with the intermediate pectoral in a female corpse. However, the origin of the intermediate pectoral is from the 3rd and $4^{\text {th }}$ ribs, while in the dissected finding there was no presence of this accessory muscle.

The innervation of the pectoralis quartus muscle has been named as the most caudal branch of the medial pectoral nerve, the "fourth intercostal nerve" or "lateral pectoral nerve," in the revised literature., ${ }^{4,6,8}$ In this case the pectoralis quartus is innervated by branches of the medial pectoral nerve that ran through the pectoralis minor. The pectoralis quartus muscle runs almost parallel to the minor pectoral and therefore may serve a similar function to that of the minor pectoral. But because it is not inserted into the coracoid process, it is almost unlikely that this variant muscle will perform the same function as the pectoralis minor during scapular stabilization. The pectoralis quartus can also contribute to the pain caused by myofascial trigger points. Trigger points are hyper-irritable points within skeletal muscle tension bands that commonly refer to pain for other areas of the body. For the effective treatment of myofascial trigger points it is necessary to know the origin of the pain. ${ }^{4,9}$ If the pain comes from a variation such as that described in the report above and the physician or physiotherapist is unaware of the presence of such a variation, the pain reference pattern may be unclear and cause an incorrect diagnosis or prolonged treatment. This variation is of vital importance to surgeons and primary care physicians, so that they are aware of the possible presence of the variant muscle so as not to confuse it with the lymph nodes or other structures when doing a physical examination or preparing for a surgical intervention. in the thoracic region. The pectoralis quartus muscle present in the present case is an important anatomical variation to be noted. Although the prevalence of pectoralis quartus already documented, the presence of a morphometry becomes fundamental to characterize its proportions and further expand the studies of these specimens and their effective cataloging, characteristics that should be considered in the clinical study and subsequent treatment of the pectoralis in patient.

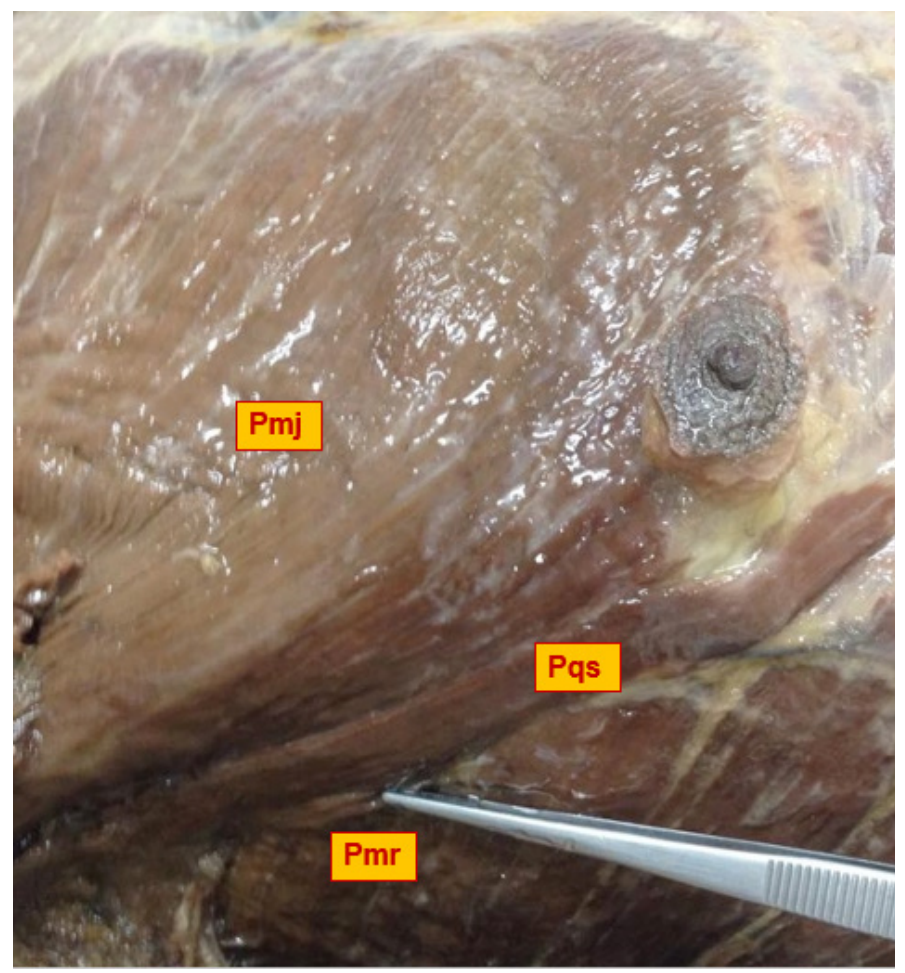

Figure 1. Dissection of right pectoral region showing Pectoralis quartus muscle. Pectoralis major muscle; Pmj. 2. Pectoralis quartus muscle; Why Pectoralis minor muscle pointed in the tweezer; Pmr. 


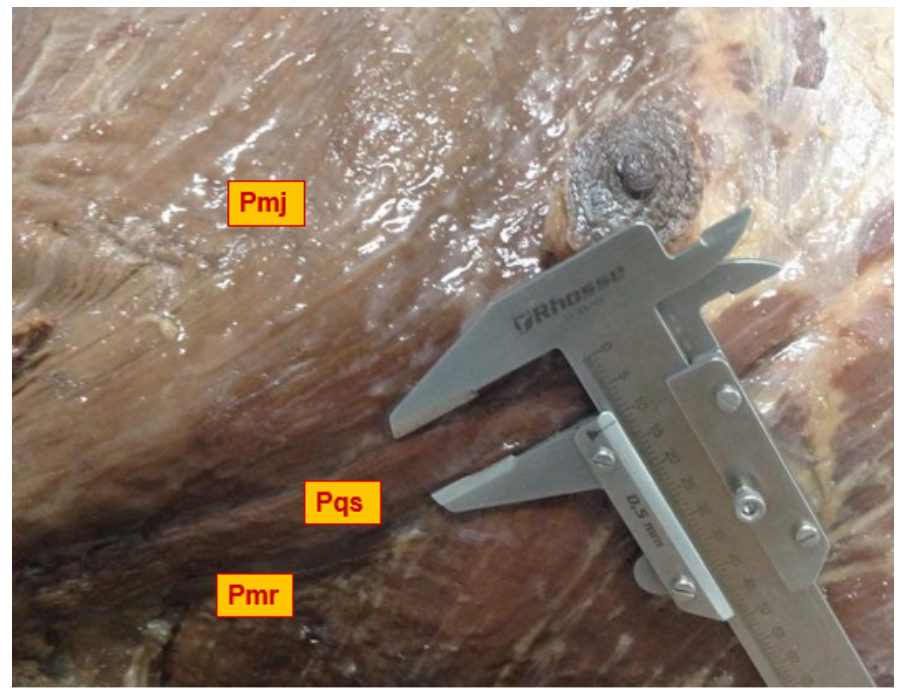

Figure 2. Dissection of right pectoral region showing Pectoralis quartus muscle. Pectoralis major muscle; Pmj. 2. Pectoralis quartus muscle evidenced by the caliper rule; Pqs. Pectoralis minor muscle; Pmr.

\section{Conclusion}

Regarding the complex variations described, we believe that knowledge of these unusual compound anatomical relationships and patterns is not restricted

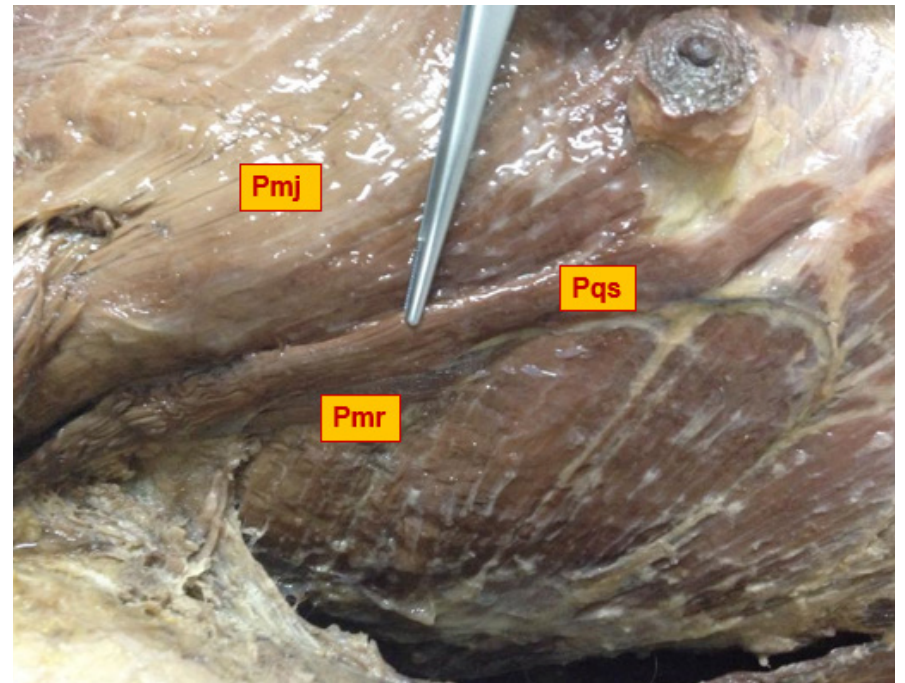

Figure 3. Dissection of right pectoral region showing Pectoralis quartus muscle. Pectoralis major muscle; Pmj. 2. Pectoralis quartus muscle pointed in the tweezer; Pqs. Pectoralis minor muscle; Pmr.

to thoracic and oncological surgeries, but should also be considered in common practices such as manipulation of the axillary and anterolateral thoracic region.

\section{References}

1. Bergman RA, Thompson SA, Afifi AK. Catalog of Human Variations. Baltimore, Urban \& Schwartzenberg. 1984; 14-15.

2. Moore KL, Dalley AF. Clinically Oriented Anatomy. $5^{\text {th }}$ Ed., Baltimore, Lippincott Williams \& Wilkins. 2006; 729-785.

3. Tountas CP, Bergman RA. Anatomic Variations of the Upper Extremity. New York, Churchill Livingstone. 1993; 85-90.

4. Hardy A. Michelle, Fabrizio Philip A. An accessory muscle of the thoracic wall. International Journal of Anatomical Variations (2009) 2: 93-95.

5. Standring S, Borley NR, Healy JC, Collins P, Crossman AR, Gatzoulis MA, Johnson D, Mahadevan V, Newell R, Wigley CB. Gray's Anatomy: The Anatomical Basis of Clinical Practice. 40th Ed., London, Elsevier. 2008; 812-813.

6. Arican RY, Coskun N, Sarikcioglu L, Sindel M, Oguz N. Co-existence of the pectoralis quartus and pectoralis intermedius muscles. Morphologie. 2006; 90: 157-159.

7. Bonastre V, Rodriguez-Niedenfuhr M, Choi D, Sanudo JR. Coexistence of a pectoralis quartus muscle and an unusual axillary arch: case report and review. Clin Anat. 2002; 15: 366-370.

8. Sawada M, Ishibashi Y, Suzuki T, Chiba S. Case reports on the pectoralis quartus and the pectoralis intermedius muscles. Kaibogaku Zasshi. 1991; 66: 99-105. (Japanese)

9. Simons DG, Travell JG, Simons LS. Myofascial Pain \& Dysfunction: The Trigger Point Manual. 2nd Ed., Philadelphia, Williams \& Wilkins.
1999; 94-177.

10. Lauth EA. 1830. Variéte's dans la distribution des muscles de l'homme. Mem Soc Hist Nat Strasbourg 1:2-5.

11. Le Bouedec G, Dauplat J, Guillot M, Vanneuville G. 1993. Le muscle pectoro-axillaire. J Chir 2:66-69.

12. Le Double AF. 1897. Traite` des variations du syste 'me musculaire de l'homme et de leur signification an point de l' anthropologie zoologique, vol I. Paris: Librairie C. Reinwald, Schleicher Fre'res. $p$ 194-286.

13. Lin C. 1988. Contracture of the chondroepitrochlearis and the axillary arch muscles. A case report. J Bone Joint Surg 70A:1404-1406. 14. Lo Cascio G. 1914. Contribution a` la morphologie de l'arc axillaire de Langer. Arch Ital Biol 62:285.

15. Ruge G. 1919. Zur Frage der Nervenversorgung des Achselbogenmuskels. Gegenbaur's Morphol Jahrb 50:341-343.

16. Sachatello CR. 1977. The axillopectoral muscle (Langer's axillary arch): a cause of axillary vein obstruction. Surgery 81:610-612.

17. Schramm U, Graf von Keyserlingk D. 1984. Studien u"ber Latissimusbo"gen des Oberarmes. Anat Anz 156:75-78.

18. Natsis K, Vlasis K, Totlis T, Paraskevas G, Noussios G, Skandalakis $P$, et al. Abnormal muscles that may affect axillary lymphadenectomy: surgical anatomy. Breast Cancer Res Treat. 2010;120(1):77-82. Epub 2009 Mar 21.
Received: March 1, 2020.

Accepted:
Corresponding author

Eduardo Poletti Camara

Email: edpcamara@gmail.com 